This paper is published in the open archive of Mid Sweden University

DIVA http://miun.diva-portal.org

with permission of the publisher

Citation for the peer-reviewed published paper:

Klinga N, Höglund H, Sandberg C. Paper properties of TMP and CTMP handsheets from spruce, as affected by the press load and temperature during sheet drying. Nordic Pulp \& Paper Research Journal. 2007;22(4):468474 .

URL to article at publishers site:

http://dx.doi.org/10.3183/NPPRJ-2007-22-04-p468-474 


\section{Paper properties of TMP and CTMP handsheets from spruce, as affected by the press load and temperature during sheet drying}

Niklas Klinga and Hans Höglund, Mid Sweden University, Sundsvall, Christer Sandberg, Holmen Paper Development Centre, Norrköping, Sweden

KEYWORDS: Laboratory sheet, TMP, CTMP, Characterization, Mechanical properties, Pressing, Drying

SUMMARY: The objective of this investigation was to evaluate how physical properties of laboratory sheets, made from different thermomechanical and chemithermomechanical pulps, depend on the pressure and temperature levels during pressing and drying. Sheets were formed from long fibre fractions, defined as the pulp retained on a 50 mesh wire in a Britt Dynamic Drainage Jar, and pressed and dried according to a number of different pressure and temperature settings. The results showed that there were large differences in the sheet properties depending on what type of method was used for pressing and drying. High freeness pulps were more sensitive than low freeness pulps to the methods used for pressing and drying. The results indicate that the difference in sheet properties between ISO and Rapid Köthen sheets may be explained by the fact that ISO sheets are wet pressed only at room temperature, the fibres are then allowed to spring back when pressure is released whereas the fibres in Rapid Köthen sheets are locked in their positions as the sheets are pressed and dried at high temperature until dry.

\begin{tabular}{l}
\hline ADDRESSES OF THE AUTHORS: Niklas Klinga \\
(niklas.klinga@holmenpaper.com.) and Hans Höglund \\
(hans.hoglund@miun.se): Mid Sweden University, Department \\
of Natural Sciences, Fibre Science and Communication \\
Network, FSCN, SE-851 70 Sundsvall, Sweden. \\
Christer Sandberg (christer.sandberg@holmenpaper.com): \\
Holmen Paper Development Centre, Braviken Paper mill, \\
SE-601 88 Norrköping, Sweden. \\
Corresponding author: Niklas Klinga
\end{tabular}

Thermomechanical and chemithermomechanical softwood pulps are often referred to as high yield pulps since the fibres contain most of the wood substances that initially enter the pulping process after debarking. Wood fibres mainly consist of cellulose, hemicelluloses and lignin. Lignin plays an important role in mechanical pulping technology, as softening of wet wood chips has been found to occur mainly due to softening of the lignin polymer. The temperature interval in which lignin softening occurs does however depend on the loading rate, i.e. the frequency of the applied force. Softening of lignin occurs in the interval between 60 and $90^{\circ} \mathrm{C}$ at low frequencies. When the frequency is higher, as is the case for fibres submitted to forces in a refiner, the softening occurs in the interval $100-170^{\circ} \mathrm{C}$ due to the fact that lignin has viscoelastic properties (Höglund et al. 1976, Irvine 1984, Irvine 1985, Olsson and Salmén 1992).

In mechanical pulping, softening of the wood chips is performed by a presteaming operation at approximately $100-155^{\circ} \mathrm{C}$. The temperature at which presteaming and refining is performed determines where in the fibre wall rupture will occur. This is due to the fact that lignin concentration is different in the different parts of the fibre wall, with the highest concentration in the middle lamella (Sundholm 1999). Pressurized refining after preheating at temperatures well above $\left(\mathrm{T} \sim 170^{\circ} \mathrm{C}\right)$ the softening temperature of lignin produces smooth fibres with a high concentration of lignin on the fibre surfaces. Here, rupture predominantly occurs in the middle lamella. Refining at lower temperatures inevitably means that fibre separation is a more stochastic process, leading to fibre rupture at different positions in the fibre wall and production of fibres with more rough surfaces (Atack 1972).

The temperature interval in which lignin softening occurs can be lowered by treating the wood chips with chemicals. This is for softwoods mostly done by wood chip impregnation with a weak solution of sodium sulphite (Atack and Heitner 1979). The $\mathrm{pH}$ at which impregnation is performed has been shown to be important for development of fibre properties during production of chemithermomechanical pulps. Impregnation at acidic conditions can for example give pulps with higher strength than impregnation at alkaline conditions at a given energy input (Argyropoulos and Heitner 1991). However, acidic conditions give problems with odour, resins and higher shive contents. Such pulps are therefore more suitable for low freeness applications, such as graphical paper where odour problems are not a big issue. After impregnation at alkaline conditions, subsequent pressurized refining leads to production of chemithermomechanical pulp, which contains long and well preserved fibres as well as low amounts of fines and shives compared to pulps from untreated chips (Höglund and Bodin 1976, Fineman 1985, Höglund and Wilhelmsson 1993).

Changing the conditions in the mechanical and chemithermomechanical pulping processes makes it possible to manufacture a broad span of pulps with very different properties, even though the same wood species are used as raw material. Fibre properties such as fibre length, fibre width, fibre flexibility, content (and quality) of fines etc will have large effects on sheet properties. Temperature and pressure affect sheet properties of high yield pulps, the temperature effect is attributed to the softening of lignin (Nygren et al. 2003).

This paper discusses how physical properties of sheets from pulps with very different fibre characteristics depend on conditions during pressing and drying. The aim was to evaluate how the sheet properties were affected by fibre flexibility. Pulps were chosen to cover a broad span of properties, from high freeness HTCTMP 
(HT means well above the softening temperature of lignin during presteaming and refining) to very low freeness TMP. Sheets from long fibre fractions (obtained from the fraction retained on a 50 mesh wire in a Britt Dynamic Drainage Jar) were pressed and dried at different pressures and temperatures, from $0 \mathrm{kPa}$ at room temperature to $400 \mathrm{kPa}$ at $93^{\circ} \mathrm{C}$. A specially designed pressing and drying unit, based on the Rapid Köthen dryer, was used in order to press and dry the sheets at higher pressure than at standard conditions (Klinga et al. 2005). Sheets from the whole pulps were made for comparisons.

\section{Background}

Test results from laboratory sheets, for example made according to the conventional ISO method or the Rapid Köthen method, sometimes yield quite different information about characteristics of mechanical and chemithermomechanical pulps (Eskilsson et al. 1976, Nygren et al. 2003). The sheet properties reach different levels depending on the method used for sheet manufacturing. This can be seen in Figs 1 to 3 which show bulk, tensile index and Z-strength respectively for a couple of pulps with very different characteristics, e.g. fibre length, fibre flexibility and fines content etc. The sheets have been manufactured according to the conventional ISO method and the Rapid Köthen method. The sheet forming procedures for these two methods are quite similar, while the pressing and drying sequences are carried out at different pressures and temperatures. Conventional ISO sheets are adhered to couch plates before being pressed at room temperature at $400 \mathrm{kPa}$, first for 5 minutes and then another 2 minutes after changing blotters. The ISO sheets are then dried and conditioned in accordance with ISO $187\left(23^{\circ} \mathrm{C}, 50 \%\right.$ R.H. $)$. Rapid Köthen sheets are pressed and dried simultaneously at $93^{\circ} \mathrm{C}$ at $96 \mathrm{kPa}$ until dry, which for $65 \mathrm{~g} / \mathrm{m}^{2}$ sheets takes approximately 8 minutes. The Rapid Köthen sheets are then conditioned in accordance with ISO 187 (ISO 187 1990, ISO 5269-1 1998, ISO 5269-2 1998).

Fig 1 shows that the magnitude of the difference between ISO and Rapid Köthen depends on what type of pulp has been evaluated. HTCTMP is a high temperature chemithermomechanical pulp which means that the wood chips have been chemically treated prior to refining at high temperature $\left(>170^{\circ} \mathrm{C}\right)$. The refining energy input and shive content are low (Höglund and Bodin 1976). Due to the manufacturing conditions, a typical HTCTMP contains a lot of long, stiff and well preserved fibres as well as small amounts of fines and shives. The large difference in bulk between ISO and Rapid Köthen sheets for HTCTMP was probably an effect of the increase in drying temperature (going from ISO to Rapid Köthen) which softened the lignin and made the long fibres more flexible. When moving towards the right side in the diagram freeness decreases, i.e. the pulps contain more highly kneaded and flexible fibres and larger amounts of fines. The magnitude of the difference between ISO and Rapid Köthen sheets then diminishes which indicates that

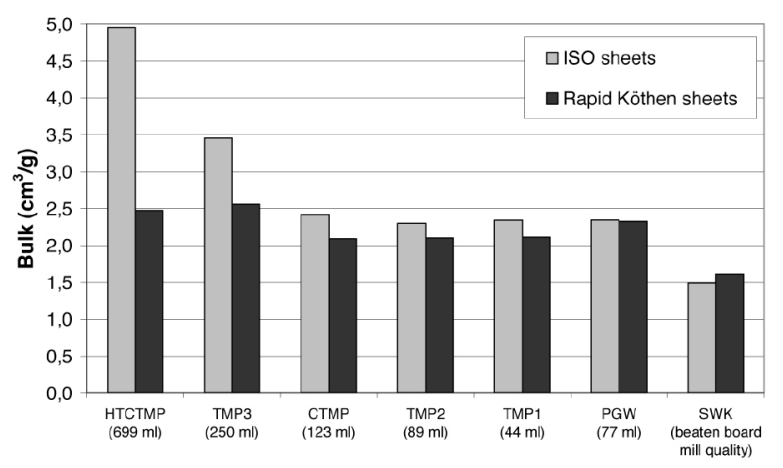

Fig 1. Bulk for ISO and Rapid Köthen sheets made from different mechanical and chemithermomechanical pulps. PGW (pressure groundwood) and SWK (softwood kraft pulp) were added to the diagram for comparison.

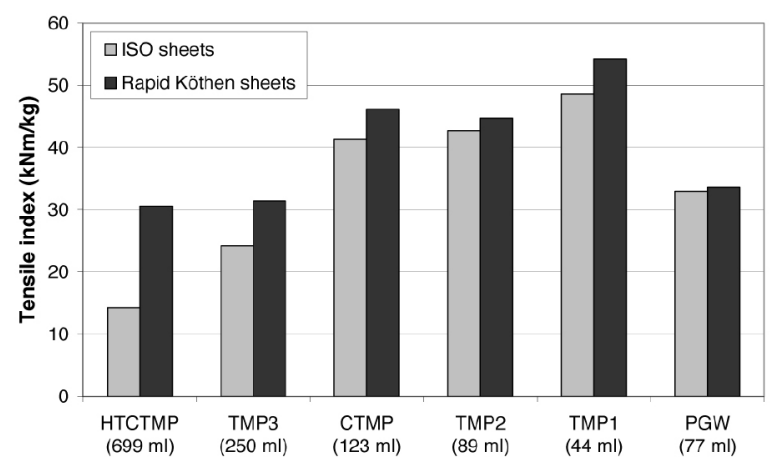

Fig 2. Tensile index for ISO and Rapid Köthen sheets made from different mechanical and chemithermomechanical pulps.

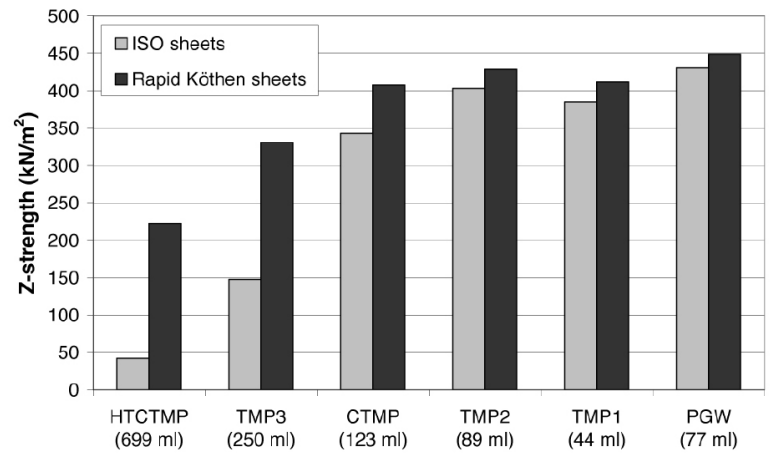

Fig 3. Z-strength for ISO and Rapid Köthen sheets made from different mechanical and chemithermomechanical pulps.

increased fibre flexibility and the bonding ability of the large amount of fines is starting to become more important than the lignin softening. Densification and thus bonding will occur more independently of temperature and pressure settings.

PGW and SWK were added to the diagram for comparison. The bulk of the PGW was expected to be lower but the relatively high bulk was believed to be an effect of the few but probably very stiff long fibres. The SWK showed an increase in bulk when going from ISO to Rapid Köthen. The reason for this is probably a combination of the effect of the lower pressure in Rapid Köthen and the fact that SWK fibres do not contain lignin.

The magnitude of the difference in tensile index between ISO and Rapid Köthen sheets, Fig 2, is quite similar to that for bulk and this applies to the Z-strength too, Fig 3. This can be explained by the same reasons as for the bulk difference. 


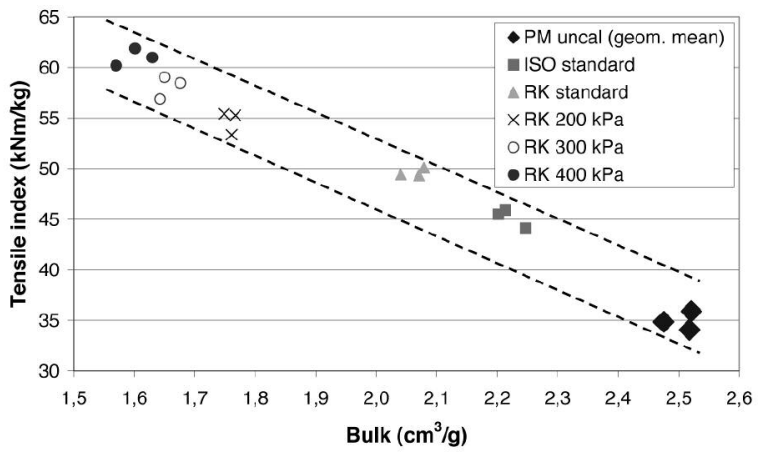

Fig 4. Comparison between uncalendered machine paper and machine chest pulp stock sheets manufactured according to different methods.

These standard methods for laboratory sheet manufacturing possess a historical importance since production and development teams have used data evaluated from them for decades to control and develop manufacturing processes. In most cases they are good enough for control purposes, where the objective of pulp testing is to detect deviations from quality specifications. However, the situation is more complicated when new types of mechanical and chemithermomechanical pulps are evaluated and compared, e.g. in research and development projects. The question is how a new pulp will perform compared to an old pulp when used on the paper or board machine, the scenario can be as follows. In Fig 2 above, the TMP1 gives 14\% higher tensile index than TMP2 when measuring ISO sheet properties. Evaluating the same pulps by measuring Rapid Köthen sheet properties suggests that TMP1 yields $21 \%$ higher tensile index than TMP2. TMP1 is the superior pulp, at least when limiting the perspective by only looking at tensile strength, but how will it perform when used on the paper machine? Will it deliver the tensile index increase promised by the ISO or the Rapid Köthen sheets? Which method delivers sheets with properties closest to the machine sheet properties? To try to shed some light upon the question, Fig 4 shows tensile index related to bulk for uncalendered machine sheets compared to machine chest pulp stock sheets made according to different methods.

The laboratory sheets were made according to the ISO and the Rapid Köthen standards. Some of the Rapid Köthen sheets were dried in a modified dryer capable of pressing the sheets at higher press loads. Fig 4 illustrates that all laboratory methods press the sheets to a lower bulk and higher tensile index compared to the machine. The fines contents in both the laboratory and the machine sheets were measured, after hot disintegration, in a Britt Dynamic Drainage Jar (50 mesh). This was done in order to assess whether there was a difference in fines content due to different fines retention. The fines contents were $36 \%$ and $41 \%$ in the laboratory sheets and the machine sheets respectively. The difference in sheet properties between machine sheets and laboratory sheets can therefore not be ascribed to a difference in fines retention. The results do, on the other hand, illustrate that the mechanical pulp in this case has a much higher strength potential than what is utilized in the actual paper machine. Neither ISO sheets nor Rapid Köthen sheets

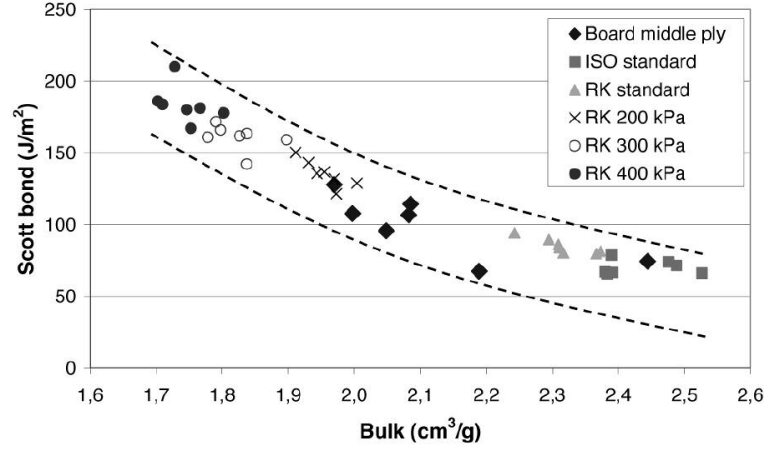

Fig 5. Comparison between the middle ply of uncalendered board and middle ply headbox pulp stock sheets manufactured according to different methods.

can be used to describe relevantly how a pulp will perform on that particular machine. The answers to the questions above must be that it is difficult to predict how big the increase in tensile index will be if using TMP1 instead of TMP2 on the machine. It is even probable that the increase would be much smaller than $14 \%$. The most relevant method would probably be to make sheets according to the ISO standard, but with lower press load during pressing.

Turning from a paper machine to a board machine point of view, Fig 5 shows Scott Bond readings related to bulk for the middle ply of uncalendered folding box board compared to middle headbox pulp stock sheets made according to different methods.

Fines content in both laboratory sheets and the middle ply of the board samples was measured, after hot disintegration, in a Britt Dynamic Drainage Jar (50 mesh). This was done in order to assess whether there was a difference in fines content due to different fines retention. The fines contents were $36 \%$ and $39 \%$ in the laboratory sheets and the middle ply respectively. Fig 5 shows that the middle ply of the board has a lower bulk and higher Scott Bond value than laboratory sheets manufactured according to ISO or Rapid Köthen. In this case, the most appropriate method would be to make Rapid Köthen sheets and press them at a pressure between 100 and 200 $\mathrm{kPa}$. The conclusion from Fig 4 and Fig 5 is that there is no laboratory sheet method that is generally relevant for all types of machines. It is however, possible to adjust pressing and drying settings for the actual laboratory methods to reach sheet property levels that are more relevant for comparisons with individual machines.

The continuation of this paper examines how sheet properties of different high yield pulps depend on the conditions during pressing and drying.

\section{Methods}

Sheets from the long fibre fractions of three pulps were pressed and dried at pressures and temperatures, varying from $0 \mathrm{kPa}$ at room temperature to $400 \mathrm{kPa}$ at $93^{\circ} \mathrm{C}$. The aim here was to evaluate how the sheet properties were affected by fibre flexibility, without the influence of fines. The sheet properties of the long fibre fractions were also compared to the sheet properties of the whole pulps. All sheets were made without any recirculation of fines. 


\section{Raw materials}

Three of the pulps described in the background section were used for further analyses. These were the HTCTMP, TMP3 and TMP1. The pulps were all unbleached high yield spruce (Picea abies) pulps, but they had very different characteristics due to different process conditions. The pulps were chosen in order to cover a broad span of properties.

The HTCTMP (CSF $699 \mathrm{ml}$ ) is a chemithermomechanical pulp used in for example multiply paperboard or tissue paper. The abbreviation HT in HTCTMP refers to a high temperature $\left(\sim 170^{\circ} \mathrm{C}\right)$, much higher than the softening temperature for lignin, during chemical impregnation and preheating in the pulping process. The TMP3 (CSF $250 \mathrm{ml}$ ) is a thermomechanical pulp used as a component in the middle ply in folding box board. The TMP1 (CSF $44 \mathrm{ml}$ ) is a thermomechanical pulp used in wood containing printing papers. The pulp characteristics are presented in Table 1.

The energy inputs during refining were approximately 600,1200 and $2400 \mathrm{kWh} /$ ton for the HTCTMP, TMP3 and TMP1 respectively.

\section{New pressing and drying equipment}

A specially designed pressing and drying equipment has been developed as a complement to the Rapid Köthen dryer. The drying principle for this new unit is similar to a standard Rapid Köthen dryer, i.e. hot water is transferred through the lid and the heat is transferred to the sheet via a silicon rubber membrane, Fig 6 .

Vacuum has to be applied below the sheet in order to enhance the removal of the water vapour and dry the sheet within reasonable time. The sheet is therefore always under pressure of $96 \mathrm{kPa}$ in the dryer since the membrane is sucked down on the sheet by the vacuum. The unit is equipped with a high-pressure pump which gives the feature of pressing the sheet with higher pressure than a standard Rapid Köthen dryer. The pressure is controlled by an adjustable valve.

The setup of this new equipment allows pressing and drying with press loads between 96 and $600 \mathrm{kPa}$ and temperatures between 60 and $95^{\circ} \mathrm{C}$.

\section{Sheet manufacturing}

The long fibre fraction trial was performed in order to evaluate how different methods affect sheet properties without the influence of fines. A specially built fractionation device was used for fractionation of the HTCTMP, TMP3 and TMP1 respectively. The fractionation device was very similar to, but larger than, a Britt Dynamic Drainage Jar. Fractionation was performed using a 50 mesh wire. In each run approximately 60 bone dry grammes of the whole pulp was added and washed with 36 litres of water. Both the whole pulps and the fractionated pulps were analysed in the Bauer McNett fractionator. The long fibre fraction pulps are distinguished from the whole pulps by the addendum $\mathrm{R} 50$ in figure legends etc. Sheets with a grammage of 65 $\mathrm{g} / \mathrm{m}^{2}$ were manufactured according to a number of different methods, from $0 \mathrm{kPa}$ at room temperature to $400 \mathrm{kPa}$ at $93^{\circ} \mathrm{C}$, Table 2 .
Table 1. Pulp characteristics.

\begin{tabular}{lrrr}
\hline Pulp & HTCTMP & TMP3 & TMP1 \\
\hline CSF (ml) & 699 & 250 & 44 \\
Fibrelength (length & & & \\
weighted, mm), FiberlabTM & 3.07 & 2.15 & 2.41 \\
BMcNett >30 (\%) & 64.77 & 34.23 & 33.48 \\
BMcNett 30-50 (\%) & 15.24 & 23.30 & 17.32 \\
BMcNett 50-100 (\%) & 7.48 & 13.53 & 9.10 \\
BMcNett 100-200 (\%) & 0.96 & 1.94 & 2.48 \\
BMcNett <200 (\%) & 11.55 & 27.00 & 37.62 \\
\hline
\end{tabular}

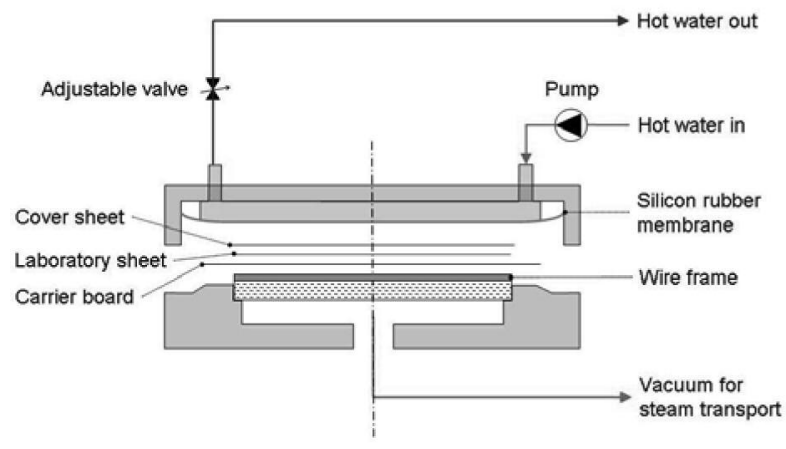

Fig 6. Schematic sketch of the pressing and drying equipment.

Table 2. Pressure and temperature settings during sheet manufacturing.

\begin{tabular}{lcc}
\hline Method & Temperature $\left({ }^{\circ} \mathbf{C}\right)$ & Pressure (kPa) \\
\hline ISO 25:0 & 25 & 0 \\
ISO 25:100 & 25 & 100 \\
ISO 25:400 (std) & 25 & 400 \\
RK 60:100 & 60 & 100 \\
RK 93:100 (std) & 93 & 100 \\
RK 60:400 & 60 & 400 \\
RK 93:400 & 93 & 400 \\
\hline
\end{tabular}

The ISO sheets were adhered to couch plates and were then, except for the ISO 25:0, pressed first for 5 minutes and then another 2 minutes after changing blotters. The Rapid Köthen sheets were pressed and dried for 8 and 16 minutes, for 93 and $60^{\circ} \mathrm{C}$ respectively, before being considered dry. The sheets made according to ISO 25:0 were, as the name implies, not submitted to any pressing. The properties of these sheets are from here on referred to as the free properties of the pulps. The properties of the whole pulp sheets, made according to ISO 25:0, ISO 25:400 (std), RK 93:100 (std) and RK 93:400 were used for comparisons.

\section{Sheet property evaluation}

The experiments were parts of a long term project with the main goal to increase bending stiffness of folding box board. One way to achieve this is to increase the bulk of the board middle layer, which is often made of thermomechanical or chemithermomechanical pulp. At the same time it is important to keep a good tensile strength and delamination strength (Fineman 1985, Tomas 1997, Bengtsson 2005). The most interesting sheet properties for this investigation were therefore bulk, tensile index and Z-strength. The measurements for thickness (single 


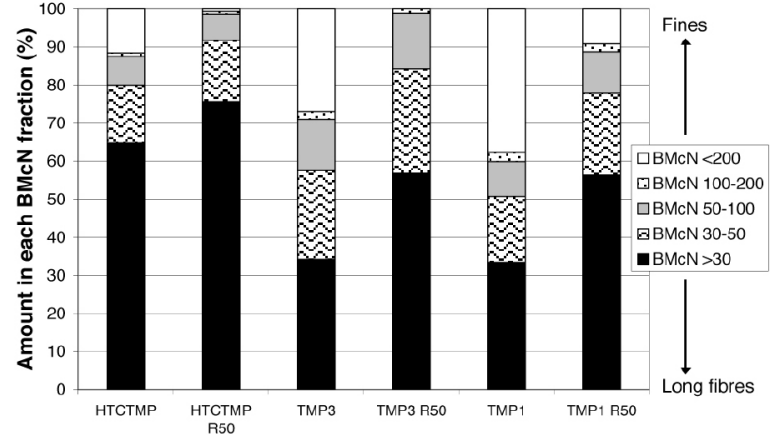

Fig 7. Bauer McNett fractions of the whole and the fractionated pulps.

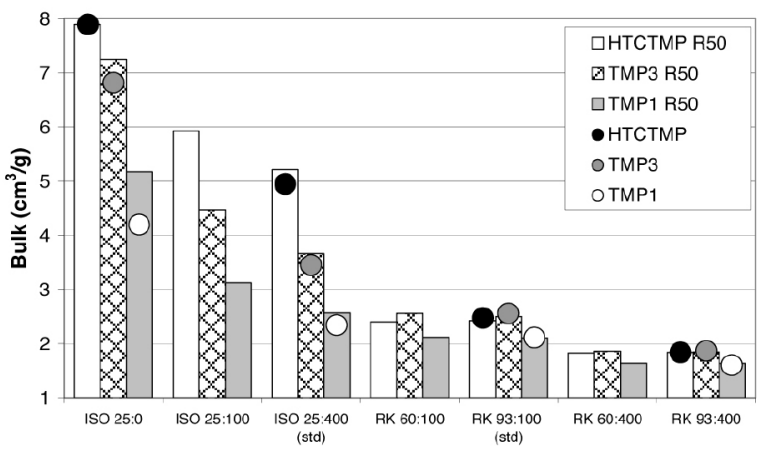

Fig 8. Bulk. The labels on the $x$-axis explain the method used for pressing and drying. The first number denotes the temperature in ${ }^{\circ} \mathrm{C}$ and the second number denotes the pressure in $\mathrm{kPa}$ during pressing.

sheet), tensile strength and Z-strength were performed according to ISO 534, SCAN-P67 and SCAN-P80 respectively.

\section{Results and Discussion}

The trial described in this paper was performed for the purpose of evaluating how different methods affect the sheet properties without the influence of fines. Fractionation was performed on a 50 mesh wire. Both the whole pulps and the fractionated pulps were analysed in the Bauer McNett fractionator. The fractionation worked quite well, and a lot of fines were removed from the pulps, Fig 7.

Sheets from the long fibre fractions were made according to the different methods presented in Table 2. Figs 8 to 10 show bulk, tensile index and Z-strength respectively. Sheet properties of the whole pulps were added for comparison and can be seen as circles inside or hovering above the columns.

There were large differences in the sheet properties depending on what temperature and pressure levels were used for pressing and drying. This can be seen for all three pulps. Sheet properties from the whole pulps were added for comparison and the differences from the long fibre fraction sheet properties show that much fines was removed during fractionation, especially for the TMP1 which contained most fines from the start.

The differences in sheet properties were extremely small when the temperature was changed between 60 and $93^{\circ} \mathrm{C}$ for the Rapid Köthen sheets. In most cases there were no differences at all. Raising pressure from 100 to $400 \mathrm{kPa}$ did however yield large changes in the sheet pro-

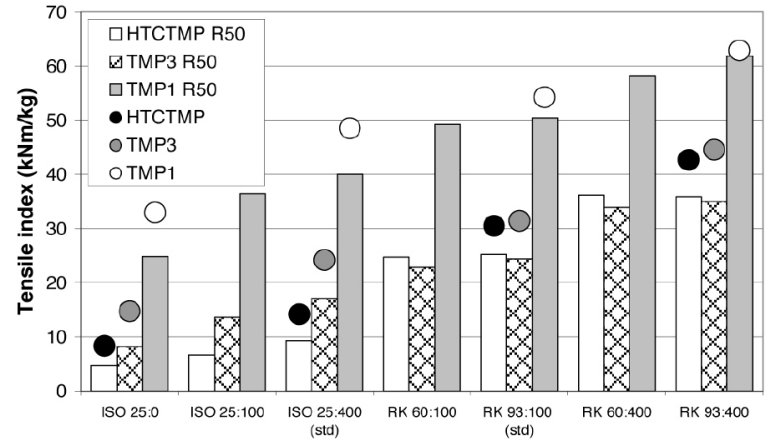

Fig 9. Tensile index. The labels on the x-axis explain the method used for pressing and drying. The first number denotes the temperature in ${ }^{\circ} \mathrm{C}$ and the second number denotes the pressure in $\mathrm{kPa}$ during pressing.

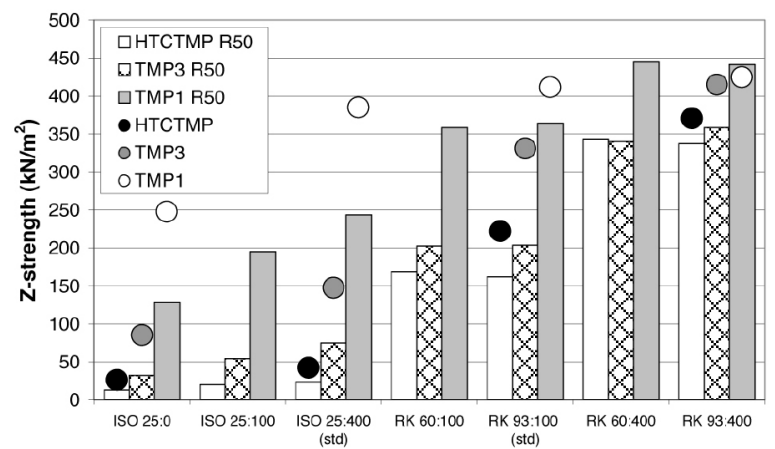

Fig 10. Z-strength. The labels on the $\mathrm{x}$-axis explain the method used for pressing and drying. The first number denotes the temperature in ${ }^{\circ} \mathrm{C}$ and the second number denotes the pressure in $\mathrm{kPa}$ during pressing.

perties. The temperature thus seems to have only affected the time required for drying. Sheet properties were equal as long as the pressure was the same while the sheet was transformed from wet to dry, at least in the temperature interval between 60 and $93^{\circ} \mathrm{C}$, which implies that $60^{\circ} \mathrm{C}$ was a sufficient temperature to achieve fibre softening.

The fact that the ISO sheets always had higher bulk and lower strength properties than the Rapid Köthen sheets might be explained by a combination of the difference in temperature during pressing and drying between the methods and the fact that ISO sheets were never fully dried during pressing. The fibres in the ISO sheets were allowed to spring back when pressure was released. This was not the case in Rapid Köthen where the fibres were locked as the sheets were pressed and dried at a high temperature until dry. This is illustrated in Figs 11 to 13, which show comparisons between free properties (ISO $25: 0$ ), i.e. sheet properties of freely dried sheets without pressure, and properties of sheets made according to the ISO 25:100, ISO 25:400 (std), RK 93:100 (std) and RK 93:400.

Moving from the left to the right in Figs 11 to 13 above, press load and temperature during pressing increases. Sheet properties for The HTCTMP, which had long and stiff fibres, were only affected slightly when pressure was increased during wet pressing (ISO) due to the fact that the fibres were allowed to spring back when pressure was released and the sheet was still wet. When pressing and drying at high temperature in the Rapid Köthen the fibres were softened and locked into their positions until the sheet was dry, the stiff HTCTMP 


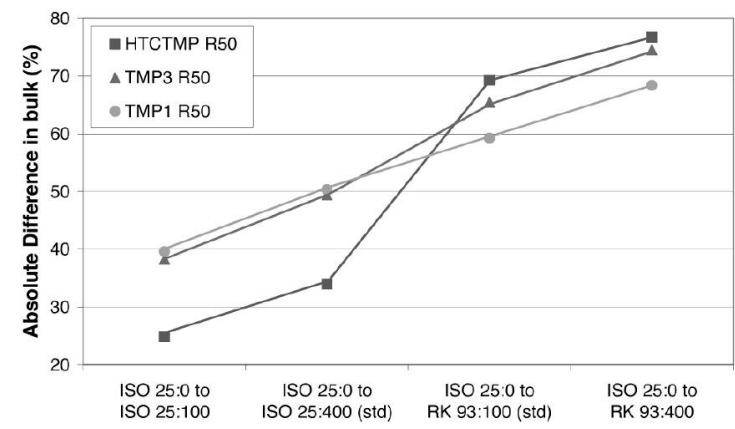

Fig 11. Bulk difference when comparing free properties (ISO 25:0) with sheet properties from ISO 25:100, ISO 25:400 (std), RK 93:100 (std) and RK 93:400.

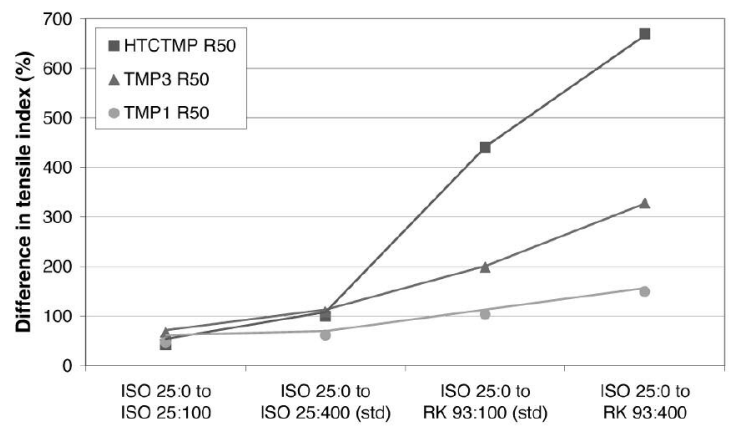

Fig 12. Tensile index difference when comparing free properties (ISO 25:0) with sheet properties from ISO 25:100, ISO 25:400 (std), RK 93:100 (std) and RK 93:400.

fibres were then affected the most with an increase in for example Z-strength of $2500 \%$.

TMP3 is a pulp used as middle ply in folding box board and is tailored to have short but still stiff fibres which is a prerequisite for achieving good formation and high bulk at a certain Z-strength. These fibres bonded to each other quite well during wet pressing. Pressing and drying in Rapid Köthen did have a significant impact on the sheet properties, even though it was not as large as for HTCTMP.

The fibres in the TMP1 are long, flexible and highly fibrillated due to the high energy input during refining. Densification and bonding of the TMP1 sheets therefore occurred more easily than for HTCTMP and TMP3. This can be seen in the figures above since the difference between Rapid Köthen and ISO sheets was smaller for TMP1 than for the other pulps.

\section{Conclusions}

For the purpose of this paper, sheets from long fibre fractions were pressed at different temperature and pressure levels with the aim of evaluating how different pressing and drying methods affect the sheet properties without the influence of fines. The essence of the results is the following:

- There were large differences in the sheet properties depending on what type of method that was used for pressing and drying.

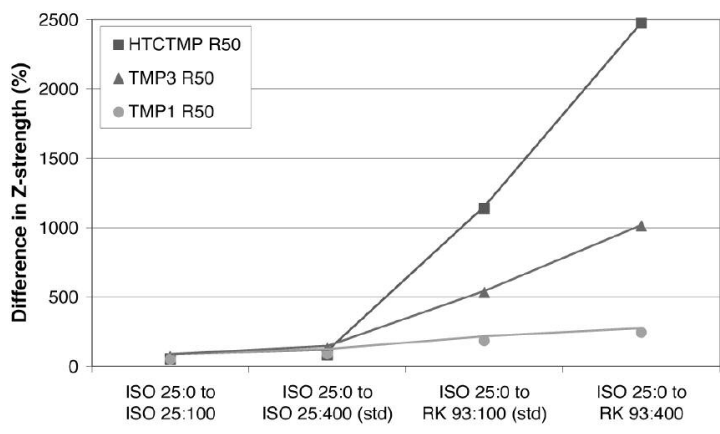

Fig 13. Z-strength difference when comparing free properties (ISO 25:0) with sheet properties from ISO 25:100, ISO 25:400 (std), RK 93:100 (std) and RK 93:400.

- High freeness pulps were more sensitive to the type of method used for pressing and drying than the low freeness pulps.

- The differences in sheet properties for the Rapid Köthen sheets were extremely small when temperature was raised from 60 to $93^{\circ} \mathrm{C}$, in most cases there were no differences at all.

- Changing the pressure from 100 to $400 \mathrm{kPa}$ in the Rapid Köthen gave large changes in the sheet properties.

- The temperature seems to affect only the drying time. Sheet properties were equal as long as the pressure was the same while the sheet was transformed from wet to dry, at least in the temperature interval between 60 and $93^{\circ} \mathrm{C}$.

- The reason that the ISO sheets always had higher bulk and lower strength properties than the Rapid Köthen sheets might be explained by the fact that the ISO sheets were never fully dried during pressing. The fibres were then allowed to spring back when the pressure was released.

- In the Rapid Köthen the fibres were locked in their positions as the sheets were pressed and dried at high temperature until dry. Sheets made from stiff fibres sprung back more when only wet pressed, and appeared to be less sensitive to pressure than sheets made from flexible fibres. The situation was the other way around when sheets were pressed and dried until dry; pulps with stiff fibres were more affected than pulps with flexible fibres by the temperature and pressure.

\section{Acknowledgements}

The authors would like to thank the staff at SCA Graphic Research for their skilful assistance in pulp and paper testing. Lorna Casson at Iggesund Paperboard Workington, Holmen $A B$, is acknowledged for linguistic revision. Holmen $A B$ and the Knowledge Foundation are acknowledged for financial support through the FSCN Industrial Mechanical Pulp Research College at Mid Sweden University. 


\section{Literature}

Argyropoulos, D.S. and Heitner, C. (1991): Ultra-High-Yield Pulping. Part VII: The effect of pH During Impregnation on the Quality of Lighly Sulphonated CTMP, J. Pulp Paper Sci. 17(5), J137.

Atack, D. (1972): On the characterization of pressurized refiner mechanical pulps, Svensk Papperstidning, 3, 89.

Atack, D. and Heitner, C. (1979): Dynamic mechanical properties of sulphonated eastern black spruce, International Mechanical Pulping Conference, Toronto, Ontario, Canada, June 11-14, 1-12.

Bengtsson, G. (2005): CTMP in production of high quality packaging board, International Mechanical Pulping Conference, Oslo, Norway, June 7-9, 7-13.

Eskilsson S., Gustafsson M. and Molin, U.-B. (1976): Egenskaper hos mekanisk massa. Del II, Jämförelse mellan olika arknings- och provningsmetoder, STFI-meddelande B 405.

Fineman I. (1985): Let the paper product guide the choice of mechanical pulp, International Mechanical Pulping Conference, Stockholm, Sweden, May 6-10, 203-214.

Höglund, H. and Bodin, 0. (1976): Modified thermo-mechanical pulp, Svensk Papperstidning, 79(11), 343.

Höglund, H., Sohlin, U. and Tistad, G. (1976): Physical properties of wood in relation to chip refining, Tappi J. 59(6), 144.

Höglund, H. and Wilhelmsson, K. (1993): The product must determine the choice of wood type in mechanical pulping, International Mechanical Pulping Conference, Oslo, Norway, June 15-17, 1-22.
Irvine, G.M. (1984): The glass transition of lignin and hemicellulose and their measurement by differential thermal analysis, Tappi J. 67(5), 118.

Irvine, G.M. (1985): The significance of the glass transition of lignin in thermomechanical pulping, Wood Sci. Technol. 19, 139.

Klinga, N., Sandberg, C. and Höglund, H. (2005): Sheet properties of high yield pulps related to different pressing and drying conditions, International Mechanical Pulping Conference, Oslo, Norway, June 7-9, 344-348.

Nygren 0., Bäck R. and Höglund, H. (2003): On characterization of mechanical and chemimechanical pulps, International Mechanical Pulping Conference, Quebec City, Canada, June 2-5, 97-103.

Olsson, A.-M. and Salmén, L. (1992): Ligninstrukturens betydelse för de viskoelastiska egenskaperna, STFI-meddelande C 229.

Sundholm, J. (1999): Mechanical Pulping, Fapet Oy, ISBN 952-5216-05-5.

SS-EN ISO 187 (1990): Paper, board and pulps - Standard atmosphere for conditioning and testing and procedure for monitoring the atmosphere and conditioning of samples.

SS-EN ISO 5269-1 (1998): Pulps - Preparation of laboratory sheets for physical testing - Part 1: Conventional sheet-former method.

SS-EN ISO 5269-2 (1998): Pulps - Preparation of laboratory sheets for physical testing - Part 2: Rapid-Köthen method.

Tomas H. (1997): Mechanical pulp in paperboard packaging, International Mechanical Pulping Conference, Stockholm, Sweden, June 9-13, 9-15.

Manuscript received May 28, 2007 Accepted June 14, 2007 